\title{
The role of thyrostimulin and its potential clinical significance
}

\author{
KARPONIS D, ANANTH S \\ Imperial College London, School of Medicine, United Kingdom \\ E-mail:dimitrios.karponis14@imperial.ac.uk
}

\begin{abstract}
Thyrostimulin is a glycoprotein heterodimer of GPA2 and GPB5, first described in 2002. It is involved in the physiological function of several tissues. Moreover, evidence points towards the ability of thyrostimulin's individual monomers to induce a biological effect, which could denote the circulatory/systemic effects of the molecule when found in higher concentrations. From the evolutionary point of view, thyrostimulin shares a binding epitope with the thyroid-stimulating hormone for the thyroid stimulating hormone receptor, whilst possessing affinity for another unique binding site on the same receptor. Although thyrostimulin can be involved in the hypothalamicpituitary-thyroid axis, its presence in various tissues in an eclectic array of different species renders it multifunctional. From weight loss via increasing metabolic rate to progression of cancer in human ovaries, it is certainly not a signaling molecule to overlook. Furthermore, thyrostimulin has been implicated in bone metabolism, acute illness, and reproductive function. In summary, to our knowledge, this is the first review dealing with the physiological role of thyrostimulin and its potential applications in the clinical practice.
\end{abstract}

Key words: thyrostimulin, glycoprotein hormone, thyroid gland, amphioxus

Thyrostimulin, an orphan glycoprotein hormone $(\mathrm{OGH})$ or corticotroph-derived glycoprotein hormone (CGH), also known as glycoprotein $\alpha 2 / \beta 5$, is a heterodimer glycoprotein first described in 2002 (Hsu et al. 2002). As the name suggests, thyrostimulin is capable of stimulating the thyroid gland and possesses even greater affinity for the thyroid-stimulating hormone receptor (TSHR) than the thyroid-stimulating hormone (TSH) itself. Thyrostimulin consists of $\alpha$ and $\beta$ subunits (GPA2 and GPB5) and is the only molecule in man to contain these specific subunits. This has sparked a great debate of thyrostimulin's in vivo function. Interestingly, the heterodimer has been found in a variety of species with different evolutionary origin and in different quantities. It is not present in every organism (e.g. ants), whereas it is virtually involved in every system of others (e.g. amphioxus). Although thyrostimulin's actions differ from species to species, the most important of them include the stimulation of the thyroid gland, development of the skeleton, regulation of hormonal systems, pathology including cancer and inflammation, and reproductive processes regulation.

While several experiments have yielded valuable results regarding the aforementioned areas, the realm of thyrostimulin is shrouded in mystery. In this review, some important findings of thyrostimulin will be discussed and the potential for translation to humans will be highlighted. We will introduce all the main aspects of thyrostimulin molecule, from evolution, to structure and function, in order to provide a balanced and comprehensive summary of the progress in the field so far and the future direction.

\section{The unique structure of thyrostimulin}

Glycoprotein hormone subunits. Glycoprotein hormones consist of $\alpha$ and $\beta$ subunits. Each subunit

Corresponding author: Dimitrios Karponis, Imperial College London, School of Medicine, United Kingdom, 230 Shepherds Bush Road, Hammersmith, London, W6 7NL; phone: +44 07518231029; e-mail: dimitrios.karponis14@imperial.ac.uk. 
is a single polypeptide chain, which is covalently attached to one or more oligosaccharides (Stockell Hartree and Renwick 1992). Thus, glycoprotein hormones are non-covalent heterodimers comprising a common $\alpha$-subunit and a hormone-specific $\beta$-subunit. In vertebrates, the $\alpha$ subunit is encoded by the same CGA gene expressed in the pituitary thyrotropic and gonadotropic cells, and hence the glycoprotein hormone a subunits in particular species display the same primary structure; the four known glycoprotein hormones in humans (hCG, LH, FSH and TSH) have identical a subunits (GPAl) (Pierce and Parsons 1981). Since the $\beta$ subunits are hormonespecific, there are specific genes encoding each $\beta$ subunit in humans (CG $\beta, \mathrm{LH} \beta, \mathrm{FSH} \beta, \mathrm{TSH} \beta)$ with six genes encoding the CG $\beta$ subunit (Cahoreau et al. 2015). The $\beta$-subunit grants the glycoprotein hormone its biological specificity. Each a subunit amino acid sequence contains ten cysteine residues, whereas each $\beta$ subunit has twelve.

GPA2 and GPB5 are two subunits, which are potentially unique for thyrostimulin and are named based on their structural similarities with known $\alpha$ and $\beta$ subunits as well as the chronology of their discovery (Hsu et al. 2002). Interestingly, GPA2 does not heterodimerize with any of the other four known $\beta$ subunits, whilst GPB5 does not heterodimerize with GPA1 (Nagasaki et al. 2006). Even though, the GPA1 and GPA2 have only 35\% primary sequence identity. In the GPA1 and GPA2, nine from ten cysteine residues have identical arrangements (Hsu et al. 2002). Moreover, GPA1 contains two N-linked oligosaccharide chains at Asn52 and Asn78, whereas human GPA2 has its two N-linked chains at Asn14 and Asn58. Some $\beta$ subunits have one $\mathrm{N}$-linked chain near the $\mathrm{N}$-terminus (LH $\beta$ and TSH $\beta$ ), while others have two (CG $\beta$ and FSH $\beta$ ). Human GPB5 belongs to the former group with its chain at Asn63 (Thotakura and Blithe 1995; Ji et al. 1997). The number of oligosaccharide chains in other species is variable. Some of amphioxus, insect, and nematode GPA2 lack the oligosaccharides, which is also true for mosquito and fly GPB5 (Dos Santos et al. 2009). Nevertheless, the oligosaccharide chains possess considerable importance for thyrostimulin's expression and receptor activation. Deletion of the oligosaccharides from both GPA2 and GPB5 decreases their expression levels - a similar finding has been observed with TSHB (Lash et al. 1992; Okajima et al. 2008).

Disruption to both oligosaccharide chains on GPA2 (Asn14 and Asn58) reduces thyrostimulin's ability to activate the TSHR (Okajima et al. 2008). Moreover, oligosaccharide chains have been shown to be important in the heterodimerization of other glycoprotein hormones. Absence of the oligosaccharide at Asn52 in GPA1 in hCG reduces the heterodimerization with CG $\beta$ by 30\% (Matzuk and Boime 1988). Curiously, the lack of either chain in GPA2 does not affect the heterodimerization with GPB5. Thus, certain subunits are perhaps less dependent on their attached oligosaccharides than others (Okajima et al. 2008).

Glycoprotein hormones contain cysteine knots, a structural motif comprised of three disulphide bridges, whereby two of the disulphide bridges and their connecting polypeptide backbones form a ring, which is threaded by the third disulphide bridge to create a knot-like structure (Alvarez et al. 2009). Cysteine knots greatly enhance the stability of the protein granting it resistance to high temperatures and proteolysis (Daly and Craik 2011). They are expressed in many different organisms. The cysteine knot in GPB5 is formed by $\mathrm{Cys}^{36}-\mathrm{Cys}^{84}$, Cys ${ }^{60}-\mathrm{Cys}^{115}$ and
Figure 1. The canonical primary structure of $\alpha$ and $\beta$ subunits in glycoprotein hormones. Triangles display the relevant positions of various Cys residues, whereas $\mathrm{N}$-linked and $\mathrm{O}$ linked saccharides are marked as "Y" (Cahoreau et al. 2015).

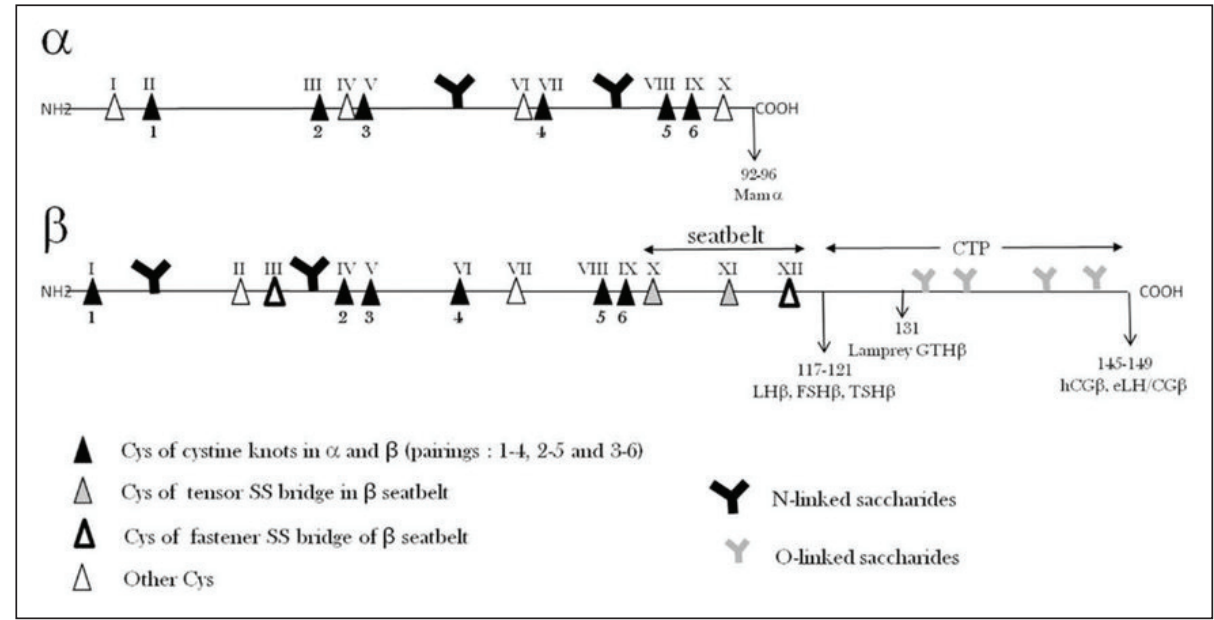


Cys $^{64}$-Cys ${ }^{117}$ disulphide bridges, whereas the knot in GPA2 is parallel to the knot in GPA1 (Hsu et al. 2002). Glycoprotein hormones are classified based on the number of amino acid residues forming the cysteine knot ring 8-aa, 9-aa, 10-aa. Thyrostimulin is an 8 -aa-ring knot-protein. Eight-aa-ring knot-proteins have seven, nine, ten or eleven cysteine residues. $\mathrm{Hu}-$ man GPH $\beta$ has twelve cysteine residues, while GPHa, GPA2, and GPB5 have ten.

The "seat belt" configuration. A distinguishing feature of the glycoprotein hormone quaternary structure is the "seat belt" formation. This occurs when the C-terminal end of the $\beta$ subunit wraps around the $\alpha$-subunit like a "seat belt", with a disulphide bridge "fastening" it in place (Fox et al. 2001). This disulphide bridge is formed by a cysteine residue in the $\mathrm{C}$-terminal region connecting to a cysteine residue in loop1. For example, in hCG, the residues 93-110 of Cterminus act as the "seat belt", wrapping around the $\mathrm{H} 2-\alpha$ loop of the a subunit, clasping it into the H1- $\beta$ loop of the $\beta$ subunit (Figure 1) (Cahoreau et al. 2015). The disulphide bridge $\mathrm{Cys}^{26}$-Cys ${ }^{110}$ (a bridge in the Cterminal region) acts as a "fastener" for the seat belt, preventing the heterodimer disassembly (Ruddon et al. 1996). Seat belt formation significantly increases the affinity of the heterodimerization between $\alpha$ and $\beta$ subunits (Lapthorn et al. 1994; Galet et al. 2004). Removing the seat belt in LH greatly increases its dissociation rate. Therefore, the typical slow rate of dissociation in glycoprotein hormones can be explained with the seat belt configuration theory (Belghazi et al. 2006).

The seat belt configuration also highlights the importance of the additional two residues in GPH $\beta$, as they are in loop 1 and at the C-terminal region, and hence form the disulphide bridge "fastener". Thyrostimulin is unique in that that its $\beta$ subunit (GPB5) contains only ten cysteine residues and so GPB5 in all species lacks the disulphide bridge fastener (Hsu et al. 2002; Alvarez et al. 2009). Thus, there is no seat belt formation in thyrostimulin. Therefore, it is questionable whether it can, indeed, heterodimerize in the circulation (Dos Santos et al. 2009). Thyrostimulin heterodimerizes only after treatment with a bifunctional reagent and it is likely that it may be less stable than other glycoprotein hormones (Shupnik et al. 1989; Nakabayashi et al. 2002). Nevertheless, GPB5 does have the $\mathrm{Cys}^{120}-\mathrm{Cys}^{127}$ disulphide bridge, which corresponds to the sixth disulphide bridge $\left(\mathrm{Cys}^{93}-\mathrm{Cys}^{100}\right)$ in $\mathrm{CG} \beta$, crucial for hCG heterodimerization (Figure 2) (Hsu et al. 2002). Therefore, others may speculate that GPB5 can probably dimerize (Hsu et al. 2002). Further research is needed to bring light into the signaling capacity of single glycoprotein hormone subunits; the ability of GPB5 to activate the TSHR is discussed in the later section.

The fact that thyrostimulin per se may not be able to heterodimerize in circulation does not exclude its potential role as an autocrine, cryptocrine or even paracrine signaling molecule. Such a role may be observed in the human pituitary gland, where GPA2 and GPB5 co-localize (Nagasaki et al. 2006). Interestingly, TSHR is also present on folliculo-stellate cells of the human anterior pituitary (Brokken et al. 2005).

Thyrostimulin and the TSHR. The relationship of thyrostimulin with the TSHR is an interesting one. The greater affinity of thyrostimulin to the TSHR in comparison with TSH results in a 30 -fold difference in bioactivity, rendering the former a more potent ligand (Sun et al. 2010). Thyrostimulin binds to two different binding sites on the TSHR; GPA2 binds to the receptor's transmembrane region, while GPB5

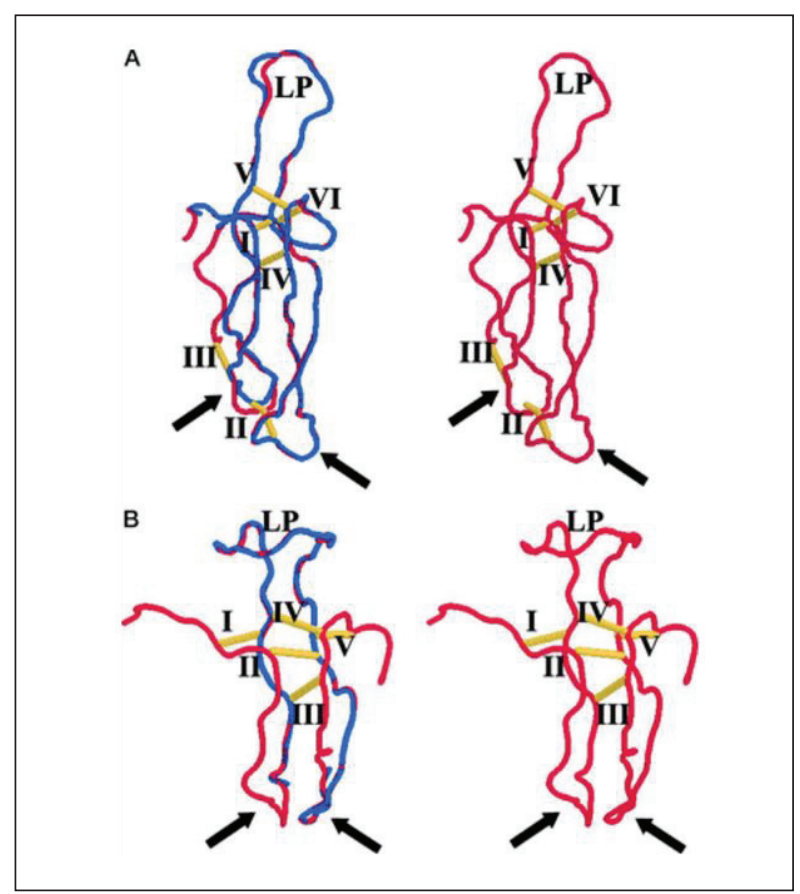

Figure 2. A structural comparison of chorionic gonadrotropin (CGa \& CG $\beta$ ) subunits with GPA2 and GPB5 (Hsu et al. 2002). A) Red trace represents the backbone of the CG $\beta$ subunit, whereas the blue trace stands for the GPB5 backbone. Golden cylinders show disulphide bridges, and are labeled I-VI. Long loops above cysteine knots are marked "LP" and the bold arrows point at hairpin loops. B) Red trace represents the backbone of the CG $\beta$ subunit, whereas the blue trace stands for the GPA2 backbone. Golden cylinders show disulphide bridges, and are labeled I-V. Long loops above cysteine knots are marked "LP" and the bold arrows point at hairpin loops. 
binds to its ectodomain (Ji et al. 1997). Others have speculated that one binding site binds to both TSH and thyrostimulin, while the other one binds only to thyrostimulin (Okada et al. 2006). The oligosaccharide chain at Asn58 is a pivotal component for TSHR activation. Hence, the Asn58 chain is most likely involved in thyrostimulin's binding to its specific site on the TSHR (Okajima et al. 2008). Additionally, fly GPA2/GPB5 has been shown to activate the DLGR1 receptor (a glycoprotein protein-coupled receptor in Drosophila melanogaster). This is noteworthy as the DLGR1 is orthologous with the TSHR (Sudo et al. 2005). However, LHR and FSHR are also orthologous with the DLRG1, but cannot bind to thyrostimulin. Furthermore, mammalian gonadotropins are capable of activating the teleost TSHR, whilst hCG possesses thyrotrophic abilities (Yoshimura and Hershman 1995; MacKenzie et al. 2009). Consequently, the specificity of TSHR for its ligands is not as high as that of other glycoprotein receptors. This evidence could support that thyrostimulin might not be specific for the TSHR. Such a concept may generate further opportunities for the signaling molecule, since it may be capable to act in the absence of the TSHR.

The role of the GPA2 in activating the TSHR upon binding to thyrostimulin remains elusive. It is known that GPB5 alone can activate human TSHR, when found in concentrations a hundred times higher than those required for thyrostimulin (as a heterodimer) to signal (Okada et al. 2006). It is also recognized that TSH is a thirty times less potent ligand of TSHR in comparison to thyrostimulin (Sun et al. 2010). Thus, one could conclude that the potency of GPB5 alone, as a ligand for the TSHR, is lower than that of TSH. However, since potency increases drastically upon heterodimerization, the GPA2 may likely possess a significant role in receptor activation. Since to the best of our knowledge, no studies have reported knocking out GPA2, which might elucidate the purpose of the monomer and to show whether it is a key for binding or signaling or for the both. At this point however, it is worth mentioning that groups have knocked out GPB5 in mice and the results are discussed in detail in the following section (Macdonald et al. 2005).

Finally, the length of GPB5's C-terminus challenges previous views about its importance in hormonal function. It has been thought that the C-terminus shortening may led to a hormonal defect, as is the case with the shortened pathogenic TSH variant, which has a C-terminus five amino acids smaller than wild-type TSH. However, the C-terminus of GPB5 is twenty amino acids shorter than the C-terminus of TSH- $\beta$ and yet is still functional.

\section{Evolutionary perspective}

Thyrostimulin has been found in several organisms of different evolutionary complexity. Examples include nematodes, insects, sea hares, tunicates, bivalves, and lancelets. General roles accepted for this molecule include thyroxin production, developmental signaling, skeletal development, and hydromineral homeostasis (Rocco and Paluzzi 2016). It has been observed in different amounts in less evolutionarily developed species. Thus, some speculate that it might represent an ancestor of the TSHR ligand (Hsu et al. 2002). However, the pleiotropic roles of thyrostimulin, together with its expression in tissues, which are distant from exposure to TSH, denote otherwise. Previous work has indeed shed a light onto the close origin of TSH, thyrostimulin, and the TSHR and their emergence after gene duplication (Force et al. 1999).

It is virtually impossible to discuss comprehensively about thyrostimulin without referring to the amphioxus. This basal chordate expresses thyrostimulin as its only glycoprotein. Whilst most invertebrates express thyrostimulin, ants, bees, and other hymenoptera do not. The role of thyrostimulin in amphioxus is pleiotropic, but most importantly is related to the embryonic development. Although considered a neuroendocrine signaling molecule, thyrostimulin is absent from Hatschek's pit, which is thought to be an equivalent of the pituitary gland in vertebrates (Tando and Kubokawa 2009a). Whether the functionality of thyrostimulin has been conserved through species is under the debate, but evidence currently points otherwise. The fact that it is found in lower amounts moving up the evolutionary complexity scale is just part of the contradicting evidence. Experiments have also shown that GPA1 chronologically succeeded thyrostimulin GPA2 in the vertebrate lineage following gene duplication (Tando and Kubokawa 2009b).

However, thyrostimulin has been detected in significant amounts in basal vertebrates, as well. More specifically, the sea lamprey has been shown to possess the molecule, which serves as an intermediate (in terms of structure-function) of the well-known glycoproteins (Sower et al. 2015). Nevertheless, this intermediate may operate as a regulator of more specialized hormones, or facilitate their emergence, in gnathostomes. One could hypothesize that water (as a habitat of these organisms) may play a role in the expression of thyrostimulin. Evidence favoring this theory is the lack of thyrostimulin in other non-human vertebrates, as well as the presence of the molecule in the venoms of marine cone snails (Robinson et al. 2017). Thyrostimulin-induced increase of meta- 
bolic rate and thus the energy demands of the target is unlikely to constitute the sole mechanism of toxicity in such venoms. A study in insects has revealed an important role of thyrostimulin in ionic and osmotic balance: the heterodimer inhibits natriuresis whilst promoting kaliuresis (Paluzzi et al. 2014). Diverging from the possible application as a poison for foreign organisms, this property of thyrostimulin is theorized to be essential for the maintenance of homeostasis in mosquitoes after a blood meal, as digestion of erythrocytes would immediately result in hyperkalaemia, an ionic state posing several dangers, with the paramount one being cardiac arrest.

In terms of GPB5, the phylogenetic analysis suggests that the murine form is the closest to human (86\% homology), whilst that found in nematodes and flies resembles human GPB5 the least (28\% homology). Finally, amphioxian GPB5 is $40 \%$ homologous to the human form. The molecular phylogenetic tree demonstrates how GPB5 is the most ancestral GPB gene, using the neighbor-joining method (Figure 3) (Tando and Kubokawa 2009a).

\section{The functional role of thyrostimulin}

As discussed earlier, thyrostimulin is involved in several different types of systems within various organisms. The sections that follow discuss the main findings in each area. Some of the key studies conducted to date are summarized in Table 1.

Thyrostimulin and the thyroid gland. For a long time, the protagonists in thyroid endocrinology were T3, T4, TSH, and thyrotropin-releasing hormone (TRH). The discovery of thyrostimulin has not changed this paradigm, but has certainly offered a potential for the addition of this molecule to the "big four". Several research groups have attempted to decipher the role of thyrostimulin in the thyroid gland, which was originally presumed to be its primary site of the action. However, it is worthwhile considering the fact that all the findings below are derived from animal models, most commonly mice.

Administration of thyrostimulin in mice elevates T4 and results in a dose-dependent hyperthyroid phenotype (Okada et al. 2006). Additional histological features include hypertrophy of not only thyroid cells, but also cells of the inner adrenal cortex (Okada et al. 2006). Use of a thyrostimulin analogue with the classical GPB5, but a slightly altered GPA2 doubles serum T4 compared to baseline (Macdonald et al. 2005). Surprisingly, knocking out GPB5 yields no overt phenotypic pathologies in mice suggesting that thyrostimulin is unlikely to be essential for the sur- vival (Okada et al. 2006; Lantz et al. 2007). However, recent findings have shown that knock-out mice for GPB5 display hypothyroxinaemia, which is more severe in juveniles, for unknown reasons (van Zeijl et al. 2010). The differences between these findings may be partly explained due to moderate deviations in the hypothalamic-thyroid (HPT) axis following GPB5 knock-out. Further possibilities include differences in the experimental protocol as well as differences in GPB5 gene expression in transgenic mice. Whilst a definitive answer as to what occurs in the absence of thyrostimulin has yet to be confirmed, it is safe to accept that thyrostimulin may have a role in the pituitary regulation and maintenance of the euthyroidism. Even though, it can stimulate the thyroid gland when present in excess. This is more challenging in an in vivo situation, because of two reasons: the concentration of circulatory thyrostimulin in humans is unknown and some experts doubt that thyrostimulin can heterodimerize in the constantly flowing bloodstream unless its subunits are present in significant amounts. Although no assay for thyrostimulin has

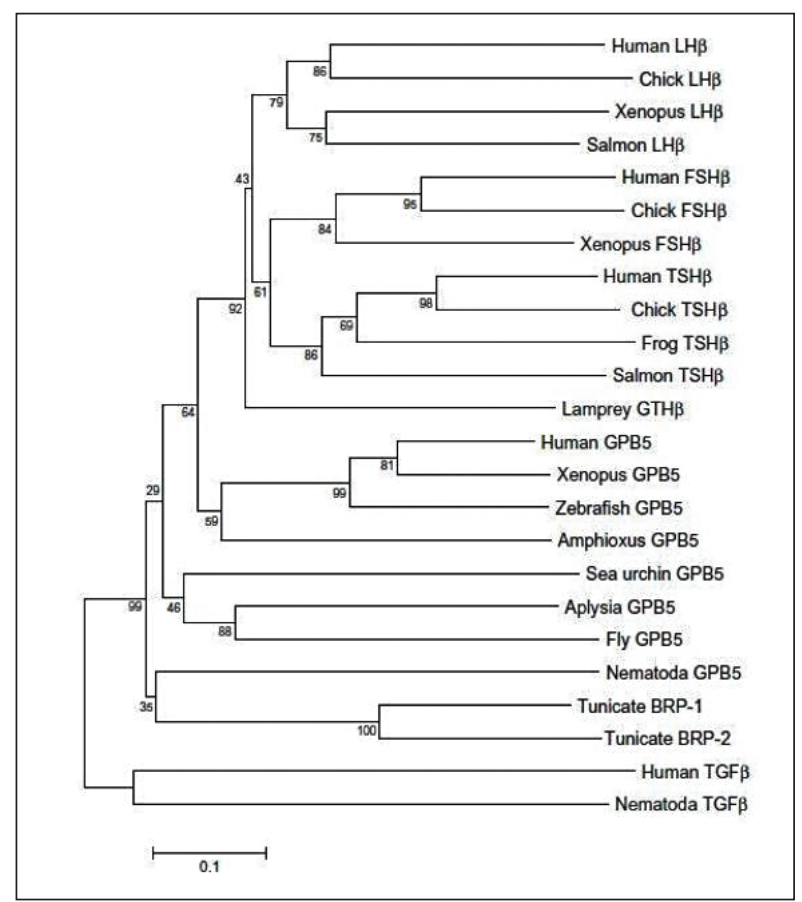

Figure 3. A molecular phylogenetic tree of GPB, with human TGF $\beta$ and nematode TGF $\beta$ as outgroups. Numbers upon branching represent bootstrap probabilities for 1000 replication trials, and the evolutionary distance (p-distance) is shown by the scale bar. This tree was created using the neighbor-joining method by Tando and Kubokawa (2009a).

Abbreviations: TGF $\beta$ - tumor growth factor beta, BRP-1 - beta related protein 1 
Table 1

A summary of the main experiments conducted regarding the function and localization of thyrostimulin in different animals in vivo and in in vitro cell lines up to date.

\begin{tabular}{|c|c|c|c|}
\hline Year/Reference & $\begin{array}{l}\text { Species/ } \\
\text { Model }\end{array}$ & Method/Technique & Outcomes \\
\hline $\begin{array}{l}2002 \\
\text { (Hsu et al. 2002) }\end{array}$ & $\mathrm{N} / \mathrm{A}$ & $\begin{array}{l}\text { Generation of tertiary structural models } \\
\text { for GPA2 and GPB5 via comparative } \\
\text { protein modeling }\end{array}$ & $\begin{array}{l}\text { GPB5 contains } 10 \text { cysteine residues and } \\
\text { so lacks the disulphide bridge "fastener" } \\
\text { required for "seat belt" formation }\end{array}$ \\
\hline $\begin{array}{l}2005 \\
\text { (Macdonald et al. } \\
\text { 2005) }\end{array}$ & Mouse & $\begin{array}{l}\text { Measurement of skull dimensions in mice } \\
\text { that globally overexpress GPB5 }\end{array}$ & $\begin{array}{l}\text { Mice that globally overexpress GPB5 } \\
\text { exhibit shortened nasal and frontal bones }\end{array}$ \\
\hline $\begin{array}{l}2006 \\
\text { (Nagasaki et al. 2006) }\end{array}$ & Rat & $\begin{array}{l}\text { Analysis of distribution of thyrostimulin } \\
\text { using qPCR (for subunits) and in situ } \\
\text { hybridisation (for subunit mRNA) }\end{array}$ & $\begin{array}{l}\text { GPA2 mRNA but virtually no GPB5 } \\
\text { mRNA is expressed in the pituitary. } \\
\text { Thyrostimulin located in eyes, testis and } \\
\text { pancreas }\end{array}$ \\
\hline $\begin{array}{l}2006 \\
\text { (Okada et al. 2006) }\end{array}$ & Hamster & $\begin{array}{l}\text { Evaluation of the binding of radiolabelled } \\
\text { thyrostimulin to transfected human TSHR }\end{array}$ & $\begin{array}{l}\text { Thyrostimulin binds to two separate sites } \\
\text { on the TSHR }\end{array}$ \\
\hline $\begin{array}{l}2009 \\
\text { (Suzuki et al. 2009) }\end{array}$ & Mouse & $\begin{array}{l}\text { Assessment of the effect of cytokines on } \\
\text { GPB5 expression }\end{array}$ & $\begin{array}{l}\text { TNFa and IL1b increased GPB } 5 \text { expression } \\
\text { by up to } 3 \text {-fold, mediated by the NF-kB } \\
\text { pathway }\end{array}$ \\
\hline $\begin{array}{l}2009 \\
\text { (Dos Santos et al. } \\
\text { 2009) }\end{array}$ & Amphioxus & $\begin{array}{l}\text { Investigation of the expression patterns } \\
\text { of thyrostimulin subunits in the basal } \\
\text { chordate }\end{array}$ & $\begin{array}{l}\text { GPB2 and GPB5 are produced in different } \\
\text { concentrations at different sites, denoting } \\
\text { potential for monomer reactivity }\end{array}$ \\
\hline $\begin{array}{l}2010 \\
\text { (van Zeijl et al. 2010) }\end{array}$ & Mouse & $\begin{array}{l}\text { Comparison of juvenile and adult GPB5 } \\
\text { knock-outs with wild types in terms of } \\
\text { thyroid parameters }\end{array}$ & $\begin{array}{l}\text { Transgenic mice display marked } \\
\text { hypothyroxinaemia, which is more severe } \\
\text { in the juvenile population }\end{array}$ \\
\hline $\begin{array}{l}2011 \\
\text { (van Zeijl et al. 2011) }\end{array}$ & Mouse & $\begin{array}{l}\text { The effect of LPS administration on GPA2 } \\
\text { and GPB5 mRNA expression }\end{array}$ & $\begin{array}{l}\text { LPS caused GPB } 5 \text { mRNA expression to } \\
\text { increase, but GPA } 2 \text { mRNA decreases }\end{array}$ \\
\hline $\begin{array}{l}2011 \\
\text { (Sellami et al. 2011) }\end{array}$ & $\begin{array}{l}\text { Drosophila } \\
\text { melanogaster }\end{array}$ & $\begin{array}{l}\text { Immunohistology and antisera studies to } \\
\text { detect the localization of thyrostimulin }\end{array}$ & $\begin{array}{l}\text { Thyrostimulin signalling involves cAMP } \\
\text { in a very similar pattern to anti-diuretic } \\
\text { hormone }\end{array}$ \\
\hline $\begin{array}{l}2014 \\
\text { (Paluzzi et al. 2014) }\end{array}$ & Mosquito & $\begin{array}{l}\text { Investigation of ion transport across the } \\
\text { gut of Aedes aegypti }\end{array}$ & $\begin{array}{l}\text { Thyrostimulin is involved in ion balance } \\
\text { by promoting kaliuresis and inhibiting } \\
\text { natriuresis }\end{array}$ \\
\hline $\begin{array}{l}2015 \\
\text { (Bassett et al. 2015) }\end{array}$ & Mouse & $\begin{array}{l}\text { Analysis of skeletal phenotype of GPB5 } \\
\text { knockout mice }\end{array}$ & $\begin{array}{l}\text { Juvenile GPB } 5 \text { knockout mice displays } \\
\text { increased bone mineralization and } \\
\text { formation, but these abnormalities } \\
\text { normalize in the adult mice }\end{array}$ \\
\hline $\begin{array}{l}2015 \\
\text { (Sower et al. 2015) }\end{array}$ & Sea Lamprey & $\begin{array}{l}\text { Through cloning, molecular and } \\
\text { phylogenetic analyses, tissue distribution } \\
\text { of lamprey glycoproteins was mapped }\end{array}$ & $\begin{array}{l}\text { First study to detect thyrostimulin in a } \\
\text { vertebrate }\end{array}$ \\
\hline $\begin{array}{l}2016 \\
\text { (Huang et al. 2016) }\end{array}$ & $\begin{array}{l}\text { Human ovarian } \\
\text { cell line } \\
\text { NIH:OVCAR-3 }\end{array}$ & $\begin{array}{l}\text { Analysis of thyrostimulin's effect on } \\
\text { NIH:OVCAR-3 cell proliferation, using the } \\
\text { BrdU incorporation assay }\end{array}$ & $\begin{array}{l}\text { Thyrostimulin promotes NIH:OVCAR-3 } \\
\text { cell proliferation, augmented by EGFR. } \\
\text { Thyrostimulin also reduces expression of } \\
\text { c-Kit. }\end{array}$ \\
\hline
\end{tabular}

fully been developed yet, a yeast two-hybrid assay has been performed to identify the presence of the molecule along with a radioimmunoassay to assess the intracellular signaling through the cAMP (Nakabayashi et al. 2002).
Despite the similar outcomes observed in the presence of TSH and thyrostimulin, they are certainly not interchangeable as indicated by their binding epitopes, sites of production, and response to the HPT axis. Thyrostimulin not only possesses higher affinity 
and the ability to bind an additional unique site on the TSHR, but also is unresponsive to an excess of TSH. Even a 500-fold excess of TSH does not alter the amount of thyrostimulin bound to the thyroid significantly. Finally, although both are produced in the adenohypophysis, different cell types are speculated to be involved in this process; thyrotrophs produce TSH, whilst thyrostimulin is believed to be produced by corticotrophs and stored in the same granules as ACTH in humans (Okada et al. 2006). The latter, though, is a subject of debate as no co-localization whatsoever has been found with ACTH or POMC expressing cells in rats, respectively (Nakabayashi et al. 2002; Nagasaki et al. 2006). Hence, it would be interesting to investigate the potential paracrine mechanism that provides the link between these two systems.

A role in weight loss, and associated risks. Through observations in transgenic mice overexpressing GPB5, thyrostimulin and compounds similar but only slightly different to the original molecule, thyrostimulin has been shown to possess therapeutic potential in diet-induced obesity (Macdonald et al. 2005). Transgenic mice indulge in increased food intake yet weigh less than their wild type (WT) counterparts, which can be attributed to the increase in metabolic rate conferred by thyrostimulin. Furthermore, mice overexpressing thyrostimulin have lower levels of blood glucose, insulin, cholesterol, and triglycerides. This is certainly not unexpected, as the action of thyroid hormones in the liver to reduce cholesterol levels has been well-established (Gullberg et al. 2000). Oddly enough, there is no significant difference in heart rate - although thyroid hormones sensitize adrenoceptors to ambient levels of their ligands, heart rate is not elevated. It is speculated that the second binding site of thyrostimulin may provide the explanation, as it may follow a different intracellular signaling cascade and produce these unexpected results.

Another very likely scenario, which may explain the results seen in GPB5KO mice (as discussed earlier) in light of the phenotype of the GPB5 overexpressing mice, is that thyrostimulin only acts locally due to the inability of its subunits to combine in the circulation. The hyperthyroid phenotype in GPB5 overexpression could be attributed to dimerization of excess GPB5 with local GPA2 already present in the thyroid, instead of direct subunit signaling through the TSHR.

The positive role of thyrostimulin in weight loss is somewhat offset by its mixed impact on the bone. Juvenile GPB5KO mice show increased bone mineral content and osteoblastic bone formation rate indicative of a negative, likely catabolic role of thyrostimulin on the bone formation and mineralization (Mac-

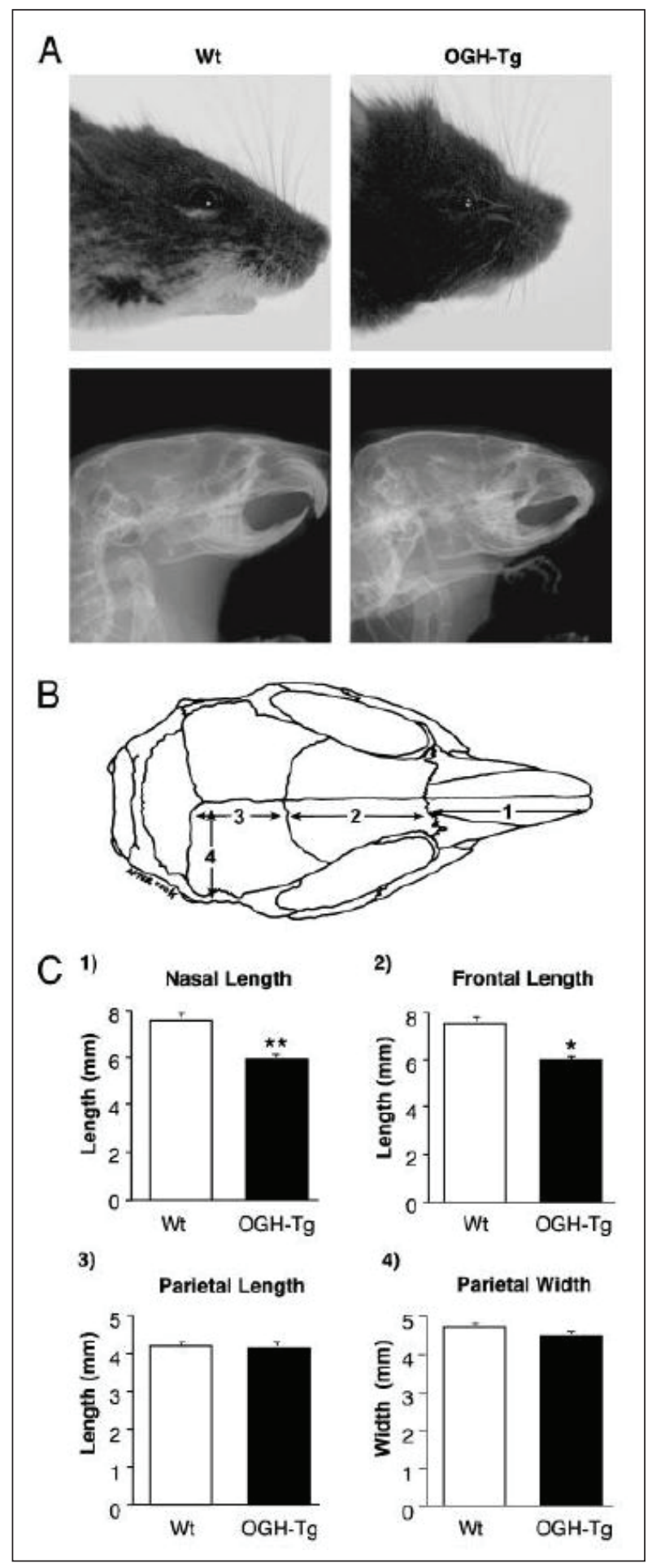

Figure 4. A comparison of nasal (1), frontal (2) and parietal (3) lengths in wild-type mice (top left) and mice overexpressing GPB5 (top right) (Macdonald et al. 2005). (A) The X-ray of murine skull. (B) The illustration of a murine skull showing the nasal (1), frontal (2) and parietal (3 and 4) parts of the structure. (C) Graphical representation of the aforementioned (in B) bone lengths and widths in different groups of mice (WT and mice overexpressing GPB5). 
donald et al. 2005). Furthermore, mice that globally overexpress GPB5 demonstrate shortening of nasal and frontal bones compared to WT, but have similar parietal bone dimensions (Figure 4) (Macdonald et al. 2005). The nasal and frontal bones in rats are derived from the neural crest, whereas the parietal bone is a mesodermal structure. Still, it is unclear why thyrostimulin retards the growth of the former but not the latter. Nevertheless, these findings demonstrate a potential trade-off between the bone mass and weight loss following thyrostimulin intake.

Interestingly, these skeletal abnormalities in juvenile GPB5KO mice are absent in their adult counterparts. Thus, the role of thyrostimulin in the bone formation reduces greatly after the completion of the development. Therefore, use of thyrostimulin as a weight loss agent could be beneficial in adults. Still, further research is needed into the mechanism of thyrostimulin in bone metabolism, as this is unclear. It does not induce a cAMP response in primary osteoblasts or osteoclasts, in addition to failing to activate noncanonical signaling pathways (Bassett et al. 2015).

Thyrostimulin in cancer progression. Epithelial ovarian carcinomas, which comprise $85 \%$ of human ovarian cancers, are derived from Ovarian Surface Epithelium (OSE) (Auersperg et al. 2001). The gonadotropins, $\mathrm{LH}$ and FSH, act on their respective receptors in the OSE to induce epithelial cell proliferation and to prevent epithelial cell apoptosis, in order to repair epithelial rupture caused by ovulation (Edmondson et al. 2006). Therefore, an excess of gonadotropins in post-menopausal women increases the risk of ovarian cancer (Cramer and Welch 1983; te Velde et al. 1998). Additionally, T3 could also stimulate ovarian cancer cell proliferation by binding to its receptor on OSE, leading to the encoding of estrogen receptor (ER) isoforms, which are strongly associated with the ovarian cancer (Rae et al. 2007). Such an association may partly explain the epidemiological links between hyperthyroidism and increased risk of ovarian cancer (Ness et al. 2000).

Thyrostimulin-TSHR signaling induces ovarian cancer cell proliferation. The human ovarian carcinoma cell line NIH:OVCAR-3 expresses both GPA2 and GPB5 suggesting that these cells also express thyrostimulin (Huang et al. 2016). NIH:OVCAR-3 expresses functional TSHR, which is also present in mammalian OSE (Sun et al. 2010). By signaling through the TSHR, thyrostimulin promotes NIH:OVCAR-3 cell proliferation to the same degree as gonadotropins. The activation of the adenylyl cyclase, MEK-ERK1/2, and PI3K-AKT signaling cascades is required for this effect. Furthermore, the activation of TSHR by thyrostimulin increases the amount of EGFR and its phosphorylation in the NIH:OVCAR-3 cells. This is noteworthy as EGFR is linked with the progression of ovarian cancer (Glaysher et al. 2013). Moreover, an EGFR inhibitor partially inhibits thyrostimulin-induced ERK phosphorylation and completely inhibits thyrostimulininduced AKT activation (Huang et al. 2016). Both of these pathways regulate epithelial ovarian cancer proliferation, further highlighting the potential role of thyrostimulin in the progression of ovarian cancer (Chan et al. 2012; Cheaib et al. 2015).

In addition, thyrostimulin reduces the expression of proto-oncogene c-Kit (Huang et al. 2016). Loss of c-Kit has been linked to breast cancer and a poor prognosis in ovarian cancer (Tonary et al. 2000; Tsutsui et al. 2006). However, little is known regarding the precise function of c-Kit in ovarian cancer cells.

The role of thyrostimulin in regulation of reproduction. As discussed earlier, thyrostimulin has been identified in several species, something behind which a reason must exist. Indeed, a series of different experiments have shed light onto a primitive function in reproduction, via thyrostimulin and the TSHR. Thyrostimulin, but not TSH, is present in rat oocytes and acts as a paracrine factor locally to regulating the reproduction (Sun et al. 2010). Intriguingly, as shown by studies in channel catfish, expression of the TSHR varies throughout the season, reaching its maximum in the spawning period before it gradually decreases again (Goto-Kazeto et al. 2009). Similar patterns have been observed in studies of seabass indicating a role of thyrostimulin in the maturation of gametes and potentially ovulation (Rocha et al. 2007). Moreover, TSHR expression has been found in fish testes, raising the possibility role for thyrostimulin in the spermiation, as well. Since thyrostimulin is more bioactive than TSH, and the latter is absent from the ovaries of some species, the function of thyrostimulin in many species becomes clearer. In fact, it has been suggested that it is more of a local regulator rather than an endocrine hormone (Sun et al. 2010). Considering the course of its evolution, as well as the uncertainties in circulatory concentration in humans, one might assume that the role of thyrostimulin in human ovaries may be more obscure.

Other roles of the heterodimer. Some studies have suggested a role for thyrostimulin during the acute illness. Proinflammatory cytokines TNFa and IL1 $\beta$ increase transcription of GPB5 by up to three times,

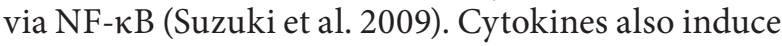
ACTH expression during stress. Coupling this notion 
with the fact that thyrostimulin is expressed in corticotrophs in humans (the site of ACTH production), one can speculate that pro-inflammatory cytokines cause its secretion along with ACTH from the corticotrophs, hinting at a biological stress response role for thyrostimulin (Okada et al. 2006).

However, others question the role of thyrostimulin during acute illness. The administration of lipopolysaccharide (LPS) in WT mice causes GPB5 mRNA expression to increase by 200 -fold in the pituitary and 4-fold in the hypothalamus. Curiously, GPA2 mRNA expression actually decreases by $75 \%$ in the pituitary and 50\% in the hypothalamus (van Zeijl et al. 2011). Therefore, GPB5 alone may likely have a role in an acute illness, rather than the heterodimer thyrostimulin. The potential role of GPB5 in acute illness could be the suppression of TSHR in the hypothalamus and pituitary, as this is not observed in GPB5KO mice (GPB5-/-), unlike their WT counterparts (van Zeijl et al. 2011). By contrast, GPB5 most likely has no effect in the liver or adipose tissue during acute illness, as LPS administration in mice is unremarkable in terms of GPB5 mRNA expression in these areas (van Zeijl et al. 2014). These findings necessitate further research into the actions of thyrostimulin's individual subunits, an area which is currently poorly understood but clearly possesses potential.

Thyrostimulin is also suspected to possess antidiuretic properties in insects. This hypothesis has been tested after noticing that thyrostimulin receptor in Drosophila melanogaster (DLGR1) is localized in areas, which secrete or absorb water. In other organisms (e.g. Caenorhabditis elegans), the GPA2 possesses some intestinal activity. Activation of the DLGR1 results in the production of intracellular cAMP, just as is the case with anti-diuretic hormones acting on the hindgut. More specifically, the researchers have suspected that the effects of thyrostimulin take place by chloride transport (Sellami et al. 2011). Therefore, it is possible that thyrostimulin may act as an antidiuretic hormone and when taking into account its ion-balancing role in mosquitoes, it may be an indispensable homeostatic regulator for some insects.

Unsurprisingly, following the wide distribution of the heterodimer, one would expect roles in a plethora of tissues. Indeed, thyrostimulin is also capable of regulating defined epidermal parameters. In human studies, it has been detected in the epidermis, which can be stimulated by TSH and thyrostimulin, even when T3 and T4 are absent. Whether thyrostimulin is capable of inducing outcomes similar to those of TSH, such as promoting epidermal differentiation, it has to be determined yet.

\section{Discussion}

Thyrostimulin possesses a novel structure. It is the only known glycoprotein hormone to be a heterodimer of the GPA2 and GPB5 subunits and so promises to be a valuable molecule for the study of this particular combination of subunits. The structure of thyrostimulin could also grant it dual-binding to the TSHR, thus partly explaining its greater affinity for the TSHR compared to TSH. However, this superior affinity is somewhat offset by thyrostimulin's reduced ability to heterodimerize in circulation, as its GPB5 subunit lacks the 2 cysteine residues necessary for the formation of the disulphide bridge fastener in the "seat belt" configuration. This is an area of current debate. The concept of thyrostimulin being a heterodimer is based on the co-localization of its subunits in the pituitary. In fact, it may serve mostly as a local regulator with autocrine and paracrine functions, rather than as a systemic hormone. Terming thyrostimulin as a signaling molecule seems to be more accurate at this point in time, as the definition of a hormone which requires production by an organ and definitive action on another tissue. Nevertheless, thyrostimulin's ability to heterodimerize in circulation could be relatively unimportant if its individual subunits can function independently in an area, which has promising evidence but needs further research. By monitoring its half-life, dissociation rate and physiological signaling, it could be ascertained whether thyrostimulin functions systemically or dissociates in the human circulation. Intravenous administration of the heterodimer in humans would provide an answer to the above question. However, due to the uncertainty in the field, such a venture is unlikely to be pursued in the immediate future.

Whilst the current opinion has suggested that thyrostimulin is not essential for the survival in most organisms, its importance is reflected when considering amphioxus, which contains thyrostimulin as its sole glycoprotein. In addition, presence in humans also denotes some form of importance, although the extent of this importance remains elusive, thyrostimulin would have become extinct through evolution if its role was unremarkable. Although it is likely that the circulating concentration of thyrostimulin in humans is very small, such an assumption has yet to be confirmed experimentally. Thyrostimulin does not act solely as a supplement to $\mathrm{TSH}$, but also as a local regulator in several tissues, most characteristically in the thyroid and ovaries. Its role in the skeletal development, bone turnover, 
and potential influence in body weight, should not be neglected. Finally, its implications in acute illness, diuresis, and cancer comprise promising aspects of thyrostimulin's physiological role with the relevance to clinical practice.

\section{Acknowledgement}

This research was not supported with any specific grant or scientific agency from the public, commercial, or not-for-profit sector.

\section{References}

Alvarez E, Cahoreau C, Combarnous Y. Comparative structure analyses of cystine knot-containing molecules with eight aminoacyl ring including glycoprotein hormones (GPH) alpha and beta subunits and GPH-related A2 (GPA2) and B5 (GPB5) molecules. Reprod Biol Endocrinol 7, 90, 2009.

Auersperg N, Wong AS, Choi KC, Kang SK, Leung PC. Ovarian surface epithelium: biology, endocrinology, and pathology. Endocr Rev 22, 255-288, 2001.

Bassett JH, van der Spek A, Logan JG, Gogakos A, Bagchi-Chakraborty J, Murphy E, van Zeijl C, Down J, Croucher PI, Boyde A, Boelen A, Williams GR. Thyrostimulin regulates osteoblastic bone formation during early skeletal development. Endocrinology 156, 3098-3113, 2015.

Belghazi M, Klett D, Cahoreau C, Combarnous Y. Nitro-thiocyanobenzoic acid (NTCB) reactivity of cysteines beta100 and beta110 in porcine luteinizing hormone: metastability and hypothetical isomerization of the two disulfide bridges of its beta-subunit seatbelt. Mol Cell Endocrinol 247, 175-182, 2006.

Brokken LJ, Bakker O, Wiersinga WM, Prummel MF. Functional thyrotropin receptor expression in the pituitary folliculo-stellate cell line TtT/GF. Exp Clin Endocrinol Diabetes 113, 13-20, 2005.

Cahoreau C, Klett D, Combarnous Y. Structure-function relationships of glycoprotein hormones and their subunits' ancestors. Front Endocrinol (Lausanne) 6, 26, 2015.

Chan DW, Hui WW, Cai PC, Liu MX, Yung MM, Mak CS, Leung TH, Chan KK, Ngan HY. Targeting GRB7/ERK/ FOXM1 signaling pathway impairs aggressiveness of ovarian cancer cells. PLoS One 7, e52578, 2012.

Cheaib B, Auguste A, Leary A. The PI3K/Akt/mTOR pathway in ovarian cancer: therapeutic opportunities and challenges. Chin J Cancer 34, 4-16, 2015.

Cramer DW, Welch WR. Determinants of ovarian cancer risk. II. Inferences regarding pathogenesis. J Natl Cancer Inst 71, 717-721, 1983.

Daly NL, Craik DJ. Bioactive cystine knot proteins. Curr Opin Chem Biol 15, 362-368, 2011.

Dos Santos S, Bardet C, Bertrand S, Escriva H, Habert D, Querat B. Distinct expression patterns of glycoprotein hormone-alpha2 and -beta5 in a basal chordate suggest independent developmental functions. Endocrinology 150, 3815-3822, 2009.

Edmondson RJ, Monaghan JM, Davies BR. Gonadotropins mediate DNA synthesis and protection from spontaneous cell death in human ovarian surface epithelium. Int J Gynecol Cancer 16, 171-177, 2006.

Force A, Lynch M, Pickett FB, Amores A, Yan YL, Postlethwait J. Preservation of duplicate genes by complementary, degenerative mutations. Genetics 151, 1531-1545, 1999.

Fox KM, Dias JA, Van Roey P. Three-dimensional structure of human follicle-stimulating hormone. Mol Endocrinol 15, 378-389, 2001.

Galet C, Lecompte F, Combarnous Y. Association/dissociation of gonadotropin subunits involves disulfide bridge disruption which is influenced by carbohydrate moiety. Biochem Biophys Res Commun 324, 868-873, 2004.

Glaysher S, Bolton LM, Johnson P, Atkey N, Dyson M, Torrance C, Cree IA. Targeting EGFR and PI3K pathways in ovarian cancer. Br J Cancer 109, 1786-1794, 2013.

Goto-Kazeto R, Kazeto Y, Trant JM. Molecular cloning, characterization and expression of thyroid-stimulating hormone receptor in channel catfish. Gen Comp Endocrinol 161, 313-319, 2009.

Gullberg H, Rudling M, Forrest D, Angelin B, Vennstrom B. Thyroid hormone receptor beta-deficient mice show complete loss of the normal cholesterol 7alpha-hydroxylase (CYP7A) response to thyroid hormone but display enhanced resistance to dietary cholesterol. Mol Endocrinol 14, 1739-1749, 2009.

Hsu SY, Nakabayashi K, Bhalla A. Evolution of glycoprotein hormone subunit genes in bilateral metazoa: identification of two novel human glycoprotein hormone subunit family genes, GPA2 and GPB5. Mol Endocrinol 16, 1538-1551, 2002.

Huang WL, Li Z, Lin TY, Wang SW, Wu FJ, Luo CW. Thyrostimulin-TSHR signaling promotes the proliferation of NIH:OVCAR-3 ovarian cancer cells via trans-regulation of the EGFR pathway. Sci Rep 6, 27471, 2016. 
Ji TH, Ryu KS, Gilchrist R, Ji I. Interaction, signal generation, signal divergence, and signal transduction of LH/CG and the receptor. Recent Prog Horm Res 52, 431-453, 1997.

Lantz M, Vondrichova T, Capretz A, Nilsson E, Frenander C, Bondeson AG, Ridderstrale M, Aberg M, Asman P, Groop L, Hallengren B. Thyrostimulin (a TSH-like Hormone) expression in orbital and thyroid tissue. Thyroid 17, 113-118, 2007.

Lapthorn AJ, Harris DC, Littlejohn A, Lustbader JW, Canfield RE, Machin KJ, Morgan FJ, Isaacs NW. Crystal structure of human chorionic gonadotropin. Nature 369, 455-461, 1994.

Lash RW, Desai RK, Zimmerman CA, Flack MR, Yoshida T, Wondisford FE, Weintraub BD. Mutations of the human thyrotropin-beta subunit glycosylation site reduce thyrotropin synthesis independent of changes in glycosylation status. J Endocrinol Invest 15, 255-263, 1992.

Macdonald LE, Wortley KE, Gowen LC, Anderson KD, Murray JD, Poueymirou WT, Simmons MV, Barber D, Valenzuela DM, Economides AN, Wiegand SJ, Yancopoulos GD, Sleeman MW, Murphy AJ. Resistance to dietinduced obesity in mice globally overexpressing OGH/GPB5. Proc Natl Acad Sci U S A 102, 2496-2501, 2005.

MacKenzie DS, Jones RA, Miller TC. Thyrotropin in teleost fish. Gen Comp Endocrinol 161, 83-89, 2009.

Matzuk MM, Boime I. The role of the asparagine-linked oligosaccharides of the alpha subunit in the secretion and assembly of human chorionic gonadotrophin. J Cell Biol 106, 1049-1059, 1988.

Nagasaki H, Wang Z, Jackson VR, Lin S, Nothacker HP, Civelli O. Differential expression of the thyrostimulin subunits, glycoprotein alpha2 and beta5 in the rat pituitary. J Mol Endocrinol 37, 39-50, 2006.

Nakabayashi K, Matsumi H, Bhalla A, Bae J, Mosselman S, Hsu SY, Hsueh AJ. Thyrostimulin, a heterodimer of two new human glycoprotein hormone subunits, activates the thyroid-stimulating hormone receptor. J Clin Invest 109, 1445-1452, 2002.

Ness RB, Grisso JA, Cottreau C, Klapper J, Vergona R, Wheeler JE, Morgan M, Schlesselman JJ. Factors related to inflammation of the ovarian epithelium and risk of ovarian cancer. Epidemiology 11, 111-117, 2000.

Okada SL, Ellsworth JL, Durnam DM, Haugen HS, Holloway JL, Kelley ML, Lewis KE, Ren H, Sheppard PO, Storey HM, Waggie KS, Wolf AC, Yao LY, Webster PJ. A glycoprotein hormone expressed in corticotrophs exhibits unique binding properties on thyroid-stimulating hormone receptor. Mol Endocrinol 20, 414-425, 2006.

Okajima Y, Nagasaki H, Suzuki C, Suga H, Ozaki N, Arima H, Hamada Y, Civelli O, Oiso Y. Biochemical roles of the oligosaccharide chains in thyrostimulin, a heterodimeric hormone of glycoprotein hormone subunits alpha 2 (GPA2) and beta 5 (GPB5). Regul Pept 148, 62-67, 2008.

Paluzzi JP, Vanderveken M, O'Donnell MJ. The heterodimeric glycoprotein hormone, GPA2/GPB5, regulates ion transport across the hindgut of the adult mosquito, Aedes aegypti. PLoS One 9, e86386, 2014.

Pierce JG, Parsons TF. Glycoprotein hormones: structure and function. Annu Rev Biochem 50, 465-495, 1981.

Rae MT, Gubbay O, Kostogiannou A, Price D, Critchley HO, Hillier SG. Thyroid hormone signaling in human ovarian surface epithelial cells. J Clin Endocrinol Metab 92, 322-327, 2007.

Robinson SD, Li Q, Bandyopadhyay PK, Gajewiak J, Yandell M, Papenfuss AT, Purcell AW, Norton RS, Safavi-Hemami H. Hormone-like peptides in the venoms of marine cone snails. Gen Comp Endocrinol 244, 11-18, 2017.

Rocco DA, Paluzzi JP. Functional role of the heterodimeric glycoprotein hormone, GPA2/GPB5, and its receptor, LGR1: An invertebrate perspective. Gen Comp Endocrinol 234, 20-27, 2016.

Rocha A, Gomez A, Galay-Burgos M, Zanuy S, Sweeney GE, Carrillo M. Molecular characterization and seasonal changes in gonadal expression of a thyrotropin receptor in the European sea bass. Gen Comp Endocrinol 152, 89-101, 2007.

Ruddon RW, Sherman SA, Bedows E. Protein folding in the endoplasmic reticulum: lessons from the human chorionic gonadotropin beta subunit. Protein Sci 5, 1443-1452, 1996.

Sellami A, Agricola HJ, Veenstra JA. Neuroendocrine cells in Drosophila melanogaster producing GPA2/GPB5, a hormone with homology to LH, FSH and TSH. Gen Comp Endocrinol 170, 582-588, 2011.

Shupnik MA, Ridgway EC, Chin WW. Molecular biology of thyrotropin. Endocr Rev 10, 459-475, 1989.

Sower SA, Decatur WA, Hausken KN, Marquis TJ, Barton SL, Gargan J, Freamat M, Wilmot M, Hollander L, Hall JA, Nozaki M, Shpilman M, Levavi-Sivan B. Emergence of an ancestral glycoprotein hormone in the pituitary of the sea lamprey, a basal vertebrate. Endocrinology 156, 3026-3037, 2015.

Stockell Hartree A, Renwick AG. Molecular structures of glycoprotein hormones and functions of their carbohydrate components. Biochem J 287 (Pt 3), 665-679, 1992.

Sudo S, Kuwabara Y, Park JI, Hsu SY, Hsueh AJ. Heterodimeric fly glycoprotein hormone-alpha2 (GPA2) and glycoprotein hormone-beta5 (GPB5) activate fly leucine-rich repeat-containing G protein-coupled receptor-1 (DLGR1) and stimulation of human thyrotropin receptors by chimeric fly GPA2 and human GPB5. Endocrinology 146, 3596-3604, 2005. 
Sun SC, Hsu PJ, Wu FJ, Li SH, Lu CH, Luo CW. Thyrostimulin, but not thyroid-stimulating hormone (TSH), acts as a paracrine regulator to activate the TSH receptor in mammalian ovary. J Biol Chem 285, 3758-3765, 2010.

Suzuki C, Nagasaki H, Okajima Y, Suga H, Ozaki N, Arima H, Iwasaki Y, Oiso Y. Inflammatory cytokines regulate glycoprotein subunit beta5 of thyrostimulin through nuclear factor-kappaB. Endocrinology 150, 2237-2243, 2009.

Tando Y, Kubokawa K. Expression of the gene for ancestral glycoprotein hormone beta subunit in the nerve cord of amphioxus. Gen Comp Endocrinol 162, 329-339, 2009a.

Tando Y, Kubokawa K. A homolog of the vertebrate thyrostimulin glycoprotein hormone alpha subunit (GPA2) is expressed in Amphioxus neurons. Zoolog Sci 26, 409-414, $2009 \mathrm{~b}$.

te Velde ER, Scheffer GJ, Dorland M, Broekmans FJ, Fauser BC. Developmental and endocrine aspects of normal ovarian aging. Mol Cell Endocrinol 145, 67-73, 1998.

Thotakura NR, Blithe DL. Glycoprotein hormones: glycobiology of gonadotrophins, thyrotrophin and free alpha subunit. Glycobiology 5, 3-10, 1995.

Tonary AM, Macdonald EA, Faught W, Senterman MK, Vanderhyden BC. Lack of expression of c-KIT in ovarian cancers is associated with poor prognosis. Int J Cancer 89, 242-250, 2000.

Tsutsui S, Yasuda K, Suzuki K, Takeuchi H, Nishizaki T, Higashi H, Era S. A loss of c-kit expression is associated with an advanced stage and poor prognosis in breast cancer. Br J Cancer 94, 1874-1878, 2006.

van Zeijl CJ, Surovtseva OV, Wiersinga WM, Boelen A, Fliers E. Transient hypothyroxinemia in juvenile glycoprotein hormone subunit B5 knock-out mice. Mol Cell Endocrinol 321, 231-238, 2010.

van Zeijl CJ, Surovtseva OV, Wiersinga WM, Fliers E, Boelen A. Acute inflammation increases pituitary and hypothalamic glycoprotein hormone subunit B5 mRNA expression in association with decreased thyrotrophin receptor mRNA expression in mice. J Neuroendocrinol 23, 310-319, 2011.

van Zeijl CJ, Surovtseva OV, Kwakkel J, van Beeren HC, Bassett JH, Williams GR, Wiersinga WM, Fliers E, Boelen A. Thyrostimulin deficiency does not alter peripheral responses to acute inflammation-induced nonthyroidal illness. Am J Physiol Endocrinol Metab 307, E527-E537, 2014.

Yoshimura M, Hershman JM. Thyrotropic action of human chorionic gonadotropin. Thyroid 5, 425-434, 1995. 